\title{
Morphology Change Study of Molybdenum Oxide from 3D to 2D Particles
}

C. Ornelas ${ }^{1 *}$, J. Lara-Romero ${ }^{1}$, C. Campos-Valadez ${ }^{2}$, C. Leyva-Porras ${ }^{3}$ and F. Paraguay-Delgado ${ }^{3}$.

${ }^{1 .}$ Facultad de Ingeniería Química, Universidad Michoacana de San Nicolás de Hidalgo, Morelia Mich., 58000, México.

2. Ingeniería en Nanotecnología, Universidad de La Ciénega del Estado de Michoacán de Ocampo, Avenida Universidad 3000, Col. Lomas de La Universidad, C.P. 59103, Sahuayo, Michoacán.

3. Centro de Investigación en Materiales Avanzados SC (CIMAV), Laboratorio Nacional de Nanotecnología, Miguel de Cervantes No.120, C.P. 31136, Chihuahua, Chih., México.

* Corresponding author: carlos.ornelas@ cimav.edu.mx

Control of morphology and crystallinity is important in materials research since many properties are linked to them. The dependence of morphology and crystallinity on the properties of molybdenum oxides have been reported for different applications such as selective oxidation of polypropylene, catalyst, adsorption of methylene blue and as precursor for its sulfurated form [1-4]. Different synthesis methods and conditions have been reported. Recently, hydrothermal method assisted by microwaves reported good results to obtain hexagonal structure and controlled shape in soft conditions [3]. In this work, we study the transformation of different morphologies from 3D (hexagonal structures) to 2D (laminar structures).

Molybdenum oxide hexagonal rods $\left(\mathrm{MoO}_{3}\right)$ were synthesized following microwave assisted hydrothermal method (MAHM) previously reported [3]. First, ammonium heptamolybdate $\left(\left(\mathrm{NH}_{4}\right)_{6} \mathrm{Mo}_{7} \mathrm{O}_{24} \cdot 4 \mathrm{H}_{2} \mathrm{O}\right)$ aqueous solution $0.3 \mathrm{M}$ was adjusted to $\mathrm{PH} 2$ by means nitric acid $2.2 \mathrm{~N}$, after, the solution was heated at $200^{\circ} \mathrm{C}$ for 20 minutes in the Multiwave PRO microwave reaction system (Anton Parr) reaching 41 bar. The molybdenum oxide hexagonal rods obtained change its morphology from 3D to 2D by external heat treatment in air atmosphere. Temperatures used for this morphology change vary from $450^{\circ} \mathrm{C}$ to $720^{\circ} \mathrm{C}$. The techniques XRD, SEM and HRTEM were used to characterize all materials.

$\mathrm{MoO}_{3}$ after MAHM synthesis is hexagonal monocristalline rods according to XRD pattern (not showed), after thermal treatment $\mathrm{MoO}_{3}$ orthorhombic 3D and 2D structures was confirmed by means of XRD (not showed), according to the results (020), (040) and (060) crystalline planes grows, while, essentially (021) decrease. Morphology characterization shows 3D terraces rods formation at low temperatures, and terraces growing effect is observed with higher temperature until achieving complete delamination at $650^{\circ} \mathrm{C}$ to produce small $2 \mathrm{D}$ structures. Temperatures higher than $650^{\circ} \mathrm{C}$ lead to the growing of $2 \mathrm{D}$ structures that continues growing until molybdenum sublimation at temperatures of $730^{\circ} \mathrm{C}$, however, a loss of material greater than $50 \%$ was observed at $720^{\circ} \mathrm{C}$. SEM images in figure 1 show the characteristic morphologies for the different temperatures tested. Figure 1 a)-c) show terraces joined to the primary hexagonal structures where more defined terraces were observed as the temperature is increased. Figures 1 d)-f) show 2D structures and their sizes get larger as the temperature is increased. A more detailed TEM study was carried out in order to understand the complete morphology change.

References:

[1] K. Schuh, W. Kleist, M, Hoj, et al, J. Solid State Chem. 228 (2015), 42-52. 
[2] M. Santos-Beltran, F. Paraguay-Delgado, A. Santos-Beltran, et al, J. Alloys Compd. 648 (2015), 445-455.

[3] M. Santos-Beltran, F. Paraguay-Delgado, R. Garcia, et al, J. Materials Science: Materials in Electronics 28.3 (2017), 2935-2948.

[4] W. Dai, B. Kheireddin, H. Gao, et al, Tribology International 102 (2016), 88-98
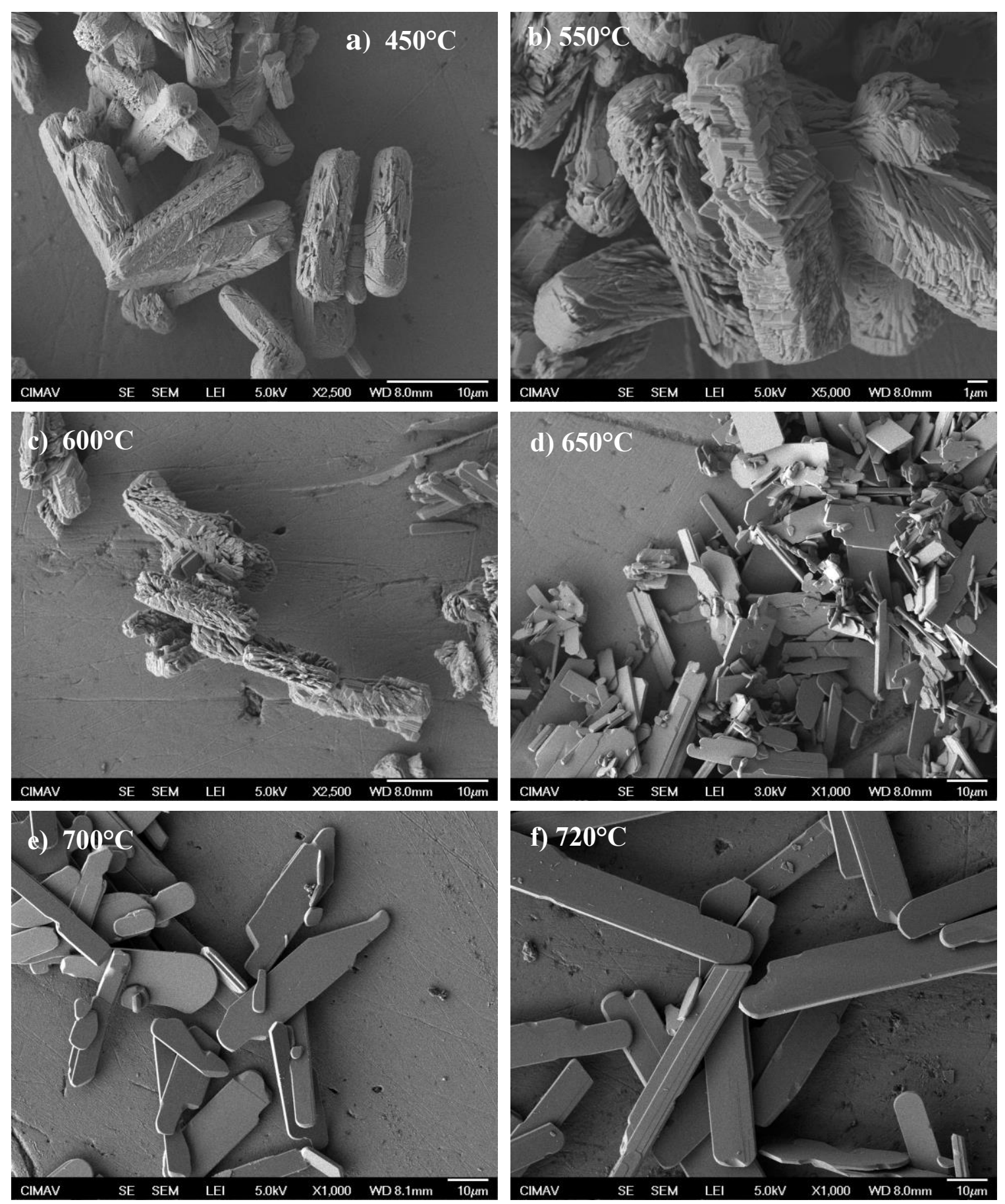

Figure 1. Molybdenum oxide synthetized by thermal treatment at: a) $450^{\circ} \mathrm{C}$, b) $550^{\circ} \mathrm{C}$, c) $600^{\circ} \mathrm{C}$, d) $\left.650^{\circ} \mathrm{C}, \mathrm{e}\right) 700^{\circ} \mathrm{C}$ and e) $720^{\circ} \mathrm{C}$. 